\title{
Practical Reflectivity as a Context for Teachers' Professional Development: a Mixed-methods Study
}

\author{
${ }^{1}$ Maria Nazaré Coimbra, ${ }^{2}$ Alcina Oliveira Martins, ${ }^{3}$ Isabel Pereira Pinto, ${ }^{4}$ Rosa Serradas Duarte \\ 1,2,3 School of of Psychology, Education and Sports \\ Lusofona University of Oporto, Portugal \\ ${ }^{4}$ School of Social Sciences, Education and Management \\ Lusofona University of Humanities and Technologies, Lisbon, Portugal \\ 1,2,3, 4 Centre for Interdisciplinary Studies in Education and Development (CeiED)
}

\begin{abstract}
This study aims at analysing the influence of practical reflectivity, as a context for professional learning, and its impact on teaching practices. Therefore, a mixed research method has been selected, based on qualitative and quantitative procedures, combining an enquiry to high school teachers and interviews to supervisors, given their privileged knowledge on the educational reality of schools and especially on the performance of teachers in classroom. These two areas of analysis, in spite of being different in terms of methodological nature, enable a comparative analysis. The study shows that all the participants, teachers and supervisors, recognize the importance of a contextualized reflection-in-action as the means to achieve greater quality of practices and an effectiveness of professional teaching development. It is also consensual the importance of a reflective teacher, who is able to question and improve his practice using investigation-in-action as basis. However, reflection is not always applied during the educational process, demanding more collaborative work between peers, pedagogical didactic update and investigation placing the student as centre. Although there is still a long way to go in terms of professional training, participants of this study perceive reflectivity as the right way to be a teacher in an educational community.
\end{abstract}

Keywords: Reflective teacher; Practical reflectivity; Teachers' professional development; Educational community; Mixed-methods study.

\section{INTRODUCTION}

Nowadays, a new pedagogical attitude is required from the teacher, enabling him not only to acquire further knowledge but also to develop personal training skills and social intervention. The demands and challenges faced by teachers are becoming more complex, given that they translate the changes that have been occurring in the economic, cultural and political fields. It is expected from the teacher to fully question his practice and develop professionally as a lifelong learner.

School has the mission of, through the means of a social useful curriculum, promote the development of the young learner and his educational success. In this context, a new paradigm for professional learning emerges, leading to the interconnection of the training processes with the School's educational processes (Robson, 2006).Therefore, research in the educational field has been focusing on professional development, in terms of its interrelation with practical reflectivity in the context of each educational community.

The complexity of a reflective improvement process, focused on the classroom and community (Hargreaves \& Shirley, 2009) justifies the present study about practical reflexivity and professional learning, exceeding the individual performance within the classroom, englobing a 
collective work shared among teachers. It matters, therefore, to analyse the potentialities of reflection and the profile of the reflexive teacher, towards the teaching responsibilities of planning, guiding and assessing an integral process of teaching and learning, in a perspective of improving the practice.

\section{Teachers' Practical Reflectivity}

The concept of practical reflection is based upon the conceptions made by Schön (Schön, 1983, 1987, 1991), on the reflective component of professional training, from practical situations. Schön considered a reflection- in- action, before, during and after action. Practice is the main line of the curriculum for teaching training, initiating a development of attitudes, skills and abilities, necessary to a "knowledge-in-action", possible through reflection (Argyris \& Schön, $1978,1996)$. Contrary to the theories of technical rationality, in which practice comes at the end of the process of development of the curriculum, in the model of teaching training as reflective professionals, teaching practice is the centre of action, reflection and construction of the teaching knowledge (Alarcão, 2009).

Reflection is not linear, but it occurs in a linear, procedural and recursive way. Reflective thinking in action and its respective reconstruction can elapse separately or simultaneously. This process involves processes that go from introspection, more personal and regularly registered in diaries, portfolios or autobiographic interviews, to collaborative reflection and discussion, between teachers, sustaining the enquiry-in-action (Moon, 2004).

The concept of reflective teaching covers attitudes and skills for reflection. Zeichner and Liston (Zeichner \& Liston, 1986) and Zeichner (Zeichner, 1993) based on the thoughts of Dewey (Dewey, 1933, 1938) enumerate three attitudes fundamental for reflective practice. The first one is the one of receptivity towards other ways of acting, admitting the possibility of making errors. The second one focus on responsibility, involving reflection on the action to be performed. The third one concerns honesty about the practice. In the search for a balance between reflection and practice, reflection- in- action occurs before, during and after action, aiming an educational improvement. This stage of reflection on what and how to evaluate practices, through the use of metareflection or awareness of the mechanisms of regulation used in the process of questioning is essential (Rodgers, 2002).

Following Dewey's ideas, Perrenoud (Perrenoud, 1998, 1999) also conceive three inherent attitudes for a reflexive teaching process. Initially, the teacher must adopt an open mind, free of preconceptions, impartial and prepared to accept new ideas. Secondly, an intellectual responsibility must be assumed, so that the teacher is able to consider, timely, the consequences of actions and standpoints previously taken. The final attitude, contributing to a reflective teaching, is enthusiasm, ability to reinvent and oppose to the routine some commitment and dynamism, in the performance of the activities. In this context, educational change focuses on the professional identities of teachers and on continuous training, enhancer of the reflective improvement of the practices, inside the classroom.

\section{School as Reflective Community}

Reflective teachers build and rebuild their knowledge with professional practice, mobilizing what they know within a collective practice. As a consequence, they are professionals who answer the demands of the contexts where they work, interpreting and adapting them to their own performance, changing their own preconceptions, if necessary (Collier et al., 2010). This perspective refers to the concept of reflective School, as a community that continuously rethinks itself, in its social mission and structure. Following these thoughts, school assumes itself as a learning educational community, through the means of enquiry and reflection-in- 
action (Senge, Cambron-McCabe, Lucas, Smith, \& Dutton, 2000). It starts from professional teaching improvement to the development, as a group, of action skills, enquiring and reflective, in the context of a learning and reflective school (Alarcão, 2009).

The most important aspect is collaborative work through team learning (Hargreaves \& Shirley, 2009; Nolan \& Hoover, 2004). The way teachers learn depends on contextual factors, which interconnect personal biographies to the educational features of interpersonal relationships of each context. In this process of self and group training, developed as a community, interpersonal relations are essential for the construction of routines and dynamics of teaching work among peers. This work of peer regulation is yet strengthened by recent performance, in Portuguese schools, of teachers who perform the role of supervisors and evaluators of their teacher colleagues (Glickman, Gordon, \& Ross-Gordon, 2001).

Current supervision demands someone with professional skills appropriate for the mediation of educational processes, namely, an ability for perception to analyse educational realities and stimulate teaching reflection. It is the duty of the supervisor to promote the enquiry in action of classroom practice, but mainly, he must be able to, along with teachers, build an environment for change and innovation, inductive of a democratic practice, reflection, enquiry and collaborative assistance in pedagogical decision-making processes (Pawlas \& Oliva, 2007). The work performed between teacher and supervisor must depend on a relation of dialogue, collaboration and reflection.

Thus, a reflection of collaborative nature can stand as a strategy of enormous training potential, by stimulating the resolution of common educational issues. Therefore, professional teaching improvement and growth increases, when the students' process of learning is assumed as a collective work. This work encompasses continuous interactions between teachers and the shared construction and reformulation of educational practices, success and failure, on school or class levels (Peel, 2005; York-Barr, Sommers, Ghere, \& Montie, 2006).

Accordingly, the ecology of personal and professional development of the teacher implies a mutual interaction between the teacher's experiences and the particularities of the educational community. According to the model of influence and regulation of Bronfenbrenner systems (Bronfenbrenner, 1979, 1994, 2005), it is essential to understand the different levels of influence that act in human development, in which school, and in a vaster extent the educational system, are included. Within this process of reciprocal influence, of ecological nature, the professional development of the teacher and the school is processed, in a process of interrelation with the environment, characterized by its contextual, continuous and specific aspects. Consequently, the construction of a shared reflection in community, following an ecological supervision receives primordial importance in the educational context, when aiming to potentiate the quality of the learning process, targeting educational success, either individual or collective, of all the elements of the same learning educational community.

\section{MATERIALS AND METHODS}

This research focuses on teachers' perceptions about the influence of practical reflectivity, as a context for professional learning, and its impact on teaching practices.

In accordance, a mixed methodology was applied, combining both quantitative and qualitative approaches (Ercikan \& Roth, 2006; Punch, 2011). The data were collected in 2014 from questionnaires applied to 80 secondary school teachers and from structured interviews to 10 supervisors, all from Oporto public schools. After transcribing the interviews, a category-based 
analysis was applied to the discourses of teachers, supported by numerical data. Categorical aggregation, a priori and a posteriori, was based in the characteristics previously referred to, in literature reviewing (Coimbra \& Martins, 2013; Stake, 1995; Yin, 2011).

This way, questionnaires were able to provide evidence of patterns amongst a large amount of teachers, while qualitative interview data deepened understanding about teachers' perceptions and opinions, how they experience practical reflectivity in schools and improve teaching and continuous professional development. The aim was to combine two types of data, with a minimal time gap, in order to obtain consistency and confirmatory results, in a questionnaire-interview comparison study (Harris \& Brown, 2010; Reams \& Twale, 2008).

\section{RESULTS AND DISCUSSION}

\section{The enquiry by questionnaire}

Results of a questionnaire enquire with the characterization of the sample are presented below. In 80 teachers, the female sex prevails. As far as age is concerned, it prevails the age level between forty and fifty, followed by, in decreasing order, teachers over 51 and the ones between 30 and 40. The prevailing academic qualification is a degree from University and most teachers claim to be in a stable professional situation. In this group of teachers some detain roles in management or supervision.

As far as the importance given by teachers to refection-action is concerned, $100 \%$ of the sample agrees that it is fundamental. The same result was obtained for reflection before, during and after action, demonstrating that there is a great awareness of the importance of reflection.

A selected set of questions and the respective results are shown below.

Table 1. Contribution of reflection to the improvement of practices.

\begin{tabular}{lc}
\hline \multicolumn{2}{l}{ Table 1. Contribution of reflection to the improvement of practices. } \\
\hline Improvement of planning & 38.7 \\
\hline Improvement of action in classroom & 25.0 \\
\hline Contextualization of practice & 15.0 \\
\hline Reformulation of practice & 15.0 \\
\hline Procedural evaluation of practice & 6.3 \\
\hline Total & 100.0 \\
\hline
\end{tabular}

In terms of the contribution of reflection to the improvement of practices, results are in table 1. According to the answers given by teachers, improvement of planning $(38,7 \%)$ and improvement of action in classroom (25.0\%) are highlighted. Both the contextualization of practice and its reformulation attained the same value $(15.0 \%)$. Finally, procedural evaluation of practice $(6.3 \%)$ appears last, showing the reality of the evaluation and self- regulation that many teachers carry unsystematically, frequently based on the students' final results. Consequently, reformulation of the practice is not implemented or is done in an incomplete way. 
Table 2. Contribution of reflection for professional development.

\begin{tabular}{ll}
\hline Questioning of practice & $\%$ \\
\hline Promotion of investigation-action & 40.0 \\
\hline Improvement of professional skills & 18.7 \\
\hline Promotion of collaborative work & 17.5 \\
\hline Promotion of individual work & 12.5 \\
\hline Pedagogical update & 6.2 \\
\hline Total & 5.0 \\
\hline
\end{tabular}

The results of table 2 are elucidative about the contribution of reflection to the development of teachers. Questioning of practice $(40.0 \%)$ is more relevant when compared to other results. It is followed, very closely, by promotion of investigation-action (18.7\%), improvement of professional skills (17.5\%) and the promotion of collaborative work (12.5\%). Promotion of individual work (6.2\%) as well as pedagogical update $(5.0 \%)$ reached the lowest numbers. This last category reveals little concern about updating, in spite of being so essential for the substantiation of reflection, to investigation-action, and, especially, for the improvement of classroom practices.

As far as teachers' insights about considering themselves as reflective teachers and why are concerned, the general answer was yes. The justifications are found in table 3.

Table 3. Justification for being a reflective teacher.

\begin{tabular}{ll}
\hline & $\%$ \\
\hline Reflection before, during and after action & 45.0 \\
\hline Reflection as the basis for action reformulation & 21.2 \\
\hline Collaborative reflection among peers & 18.8 \\
\hline Teacher as reseacher of the practices & 12.5 \\
\hline Longlife learner & 2.5 \\
\hline Total & 100.0 \\
\hline
\end{tabular}

A justification has been requested to each teacher. Reflection before, during and after action $(45.0 \%)$ was the predominant given answer. Next, teachers present reflection as the basis for action reformulation (21.2\%) and collaborative reflection among peers (18.8\%) as a valid justification. The teacher as researcher of practices $(12.5 \%)$ is revealed to be less common among teachers, corroborating the results of subcategory promotion of investigation-action $(18.7 \%)$ in table 2 . Among the few (5.0\%) that do not consider themselves to be reflective teachers, the prevailing justification is lack of time due to the high number of classes. In general, teachers reveal answers that follow the lines of the advantages of reflection-action as featured by Schön (Schön, 1987, 1991). However, results show that they not always practice them in a systematic way. 


\section{Enquiry by Interview}

The enquiry by interview was carried out to 10 supervisors. Theirs duties are the evaluation of teachers' performance, including classroom observation, which gives them a privileged position for analyzing the performance of reflective teachers' action.

The analysis of the interviews considered four different categories sustained by the revision of literature. The selected categories consider the process of reflection in action, the potential of reflection of the practices, the profile of the reflective teacher and the improvement of professional abilities. Counting of simple occurrences in the transcribed discourses, after respective semantic carve, was made for each category and subcategory, considering the corpus in analysis. Considering the first category of analysis, reflection in action, results are displayed in table 4.

Table 4. Substantiation of the process of reflection-in-action.

\begin{tabular}{lc}
\hline Category 1 Process of reflection in action & \\
\hline Subcategories & Oc. \\
\hline Reflection before action & 13 \\
\hline Reflection during action & 8 \\
\hline Reflection after action & 10 \\
\hline
\end{tabular}

Subtitle: Oc. - Occurrence

All supervisors consider that teachers perform reflection before action, however the same does not happen for reflection after action and, mainly, for reflection during action. From a total of 31 discursive occurrences, the majority indicates reflection before action (13), referring to the decisions to be taken along the planning process, previous to pedagogical work. These numbers are considerably different from the ones obtained from the enquiry by questionnaire in which reflection before, during and after action reaches $100.0 \%$, although the different moments of the reflective process already present results of $45.0 \%$ (table3). The difficulty of implementing reflection during action is confirmed due to the simultaneity of actions that it implies, as it was explained by the supervisors.

Sup. 2: "For reflection before action there is no problem. But reflection during action is difficult to observe, unless teachers verbalize later on their decisions in the classroom or register in diaries and portfolios (...) The problem is with reflection after action because teachers avoid it, if it is done among peers or with a supervisor. Some, instead of understanding it as an opportunity to improve practice, consider it to be a personal criticism".

Sup. 3: "Reflection in action is not easy. The majority of the teachers I observed in classroom, perform some kind of previous reflection when selecting curricular contents and strategies for annual or classroom planning. But reflection during action is not interiorized. And reflection after action is, many times, performed only when there is lesson observation, by a supervisor. It is clear that teachers make comments like "The lesson went well" or "This lesson could have been better" or yet "Students didn't participate today". But this is not a grounded reflection. These comments frequently heard in the teachers' room, soon are forgotten and nothing changes".

Previous examples show that, according to the perceptions of the supervisors, there is some resistance of teachers towards reflection after action, mostly, in the moment of performing 
evaluation. Both quoted supervisors underline that reflection processes are not still interiorized by the teachers. Very often, they are reduced to a utilitarian reflection used to plan and perform the activities. Being so, teachers should be conscious about the potential of practice reflection.

Table 5. Identification of the potential of practical reflectivity.

\begin{tabular}{ll}
\hline Category 2 Potential of the practical reflexivity & \\
\hline Subcategories & Oc. \\
\hline Substantiation of decision-making & 11 \\
\hline Contextualization of pedagogical action & 10 \\
\hline Relation between theory with practice & 9 \\
\hline Pedagogical update & 8 \\
\hline Grounded reformulation of action & 7 \\
\hline Questioning of teachers' action & 6 \\
\hline Integration in a process of investigation- in- action & 6 \\
\hline Diversification of educational strategies & 5 \\
\hline Evaluation of the teaching process & 3 \\
\hline Promotion of the student's development & 2 \\
\hline
\end{tabular}

For category 2, potential of practical reflectivity, results are presented in table 5, totalizing 67 occurrences. Substantiation of decision-making is referred by the majority of the supervisors (11) properly contextualized (10), as it is the relation between theory and practice (9). It is still meaningful the influence of a reflective attitude in the pedagogical update (8). According to the supervisors, teachers' reflection does not always promote a grounded reformulation of action (7), which means that it is still difficult the change of teaching methods and the diversification of educational strategies (5) according to an integrated reflection in the learning and teaching process. In agreement, the potential of questioning teachers' action (6), together with the integration in a process of investigation- in- action (6) are not always taken into account. Regarding the evaluation of the teaching process (3) it is mentioned by only a few supervisors showing not the potential, but the fragilities of the teacher's procedural reflection, still very restricted to the planning and grounding of the activities.

One aspect that can be highlighted is the focus attributed to the potential of teachers' reflection over the student's reflection. Indeed, the focus on the student only occurs for one single subcategory of analysis, promoting the development of the student (2). Despite the fact that innumerous authors mention joint development of teacher and student as a potential of reflection, such is not confirmed by supervisors in their discourses or by teachers in their questionnaires. Some significant excerpts related to this category and respective subcategories, taken from the discourses of the supervisors are transcript bellow:

Sup. 5: "For both teachers and supervisors, reflection is not easy. For teachers, the majority of the classes are heterogeneous, so it becomes difficult to reflect on pedagogical decisionmaking, considering the context and the difficulties of the students. (...) For the supervisors, it 
is also very difficult to lead teachers to reflect about their performance, when there is classroom observation (...)."Unfortunately, some teachers don't accept criticism and what could be a productive reflection, becomes for all a source of problems."

Sup. 9: "Reflection must relate theory to practice. Sometimes I consider that we don't worry enough about pedagogical updating, unless when there are training courses. Much of what teachers and supervisors do is already internalized, year after year, always the same, with no variation (...) Reflection can help us to see what needs change and to vary strategies. (...) Although the time that teachers have available for research is not much, the ideal is for each teacher to do a self- investigation- in- action and is able to question the practices".

These examples reveal the potential of reflection, both for teachers and supervisors. Potential of reflection in decision-making, in the relation between theory and practice, in the relevance given to context, in investigation- in- action and in the questioning of the practices are highlighted, meeting the perceptions of the teachers who participated in the enquiry by questionnaire. Nonetheless, the difficulties experienced by supervisors are clear in the discourse of the first quoted supervisor, when those difficulties promote a reflection that challenges attitudes which are rooted among teachers. Therefore, it is essential to participate in the construction of a reflective teacher.

Table 5. Description of the profile of the reflective teacher.

Category 3 Profile of the reflective teacher.

\begin{tabular}{l|l}
\hline Subcategories & Oc. \\
\hline Reflection before, during and after action & 12 \\
\hline Reflection as a basis for action reformulation & 10 \\
\hline Collaborative reflection among peers & 9 \\
\hline Sharing the work in community & 8 \\
\hline Teacher as researcher of the practices & 7 \\
\hline Work on research in action & 7 \\
\hline Commitment to auto and hetero learning & 5 \\
\hline Lifelong learner & 2 \\
\hline
\end{tabular}

For the third category, profile of the reflective teacher, results are inserted in table 6, totalizing 60 occurrences. For the supervisors, it is clear the predominance of systematic reflection, before, during and after action (12) as the basis of action reformulation (10), performed collaboratively among peers (9). This reflection implies sharing the work within the community (8), of a teacher investigator of practices (7), capable of developing a work of investigation-in-action (7). Finally, the profile of the reflective teacher presupposes commitment to auto and hetero learning (5), englobing continuous training, both formal and resultant of practice reflectivity, within a perspective of reflective school, in a learning community, to be undertook throughout (2). This profile is outlined by supervisors in the following way:

Sup.1: "The reflective teacher is the one who is capable of thinking critically all the moments of the educational action, within a process of continuous questioning. He is capable of sharing 
doubts and progression with his educational community."

Sup.6: "The most significant feature of the reflective teacher is reflection before, during and after practices, in a way that he is able to maintain or change action. Most of all, it is important that after action, he is capable of investigating its effectiveness and ask: What do I need to change?"

Sup.10: "The reflective teacher works in team, investigates and listens to the opinions of students, teachers or supervisors. He is capable of changing his plan of action, based in authors, theories and especially in self action- investigation, in the classroom. He is an eternal learner, always in the search for a more effective strategy and a more attractive projects for his students".

The profile of the reflective teacher, built by the supervisors, combines highly complex features, also referred to, though only partially, by teachers who participated in the enquiry by questionnaire. For that reason, the last supervisor to be quoted uses the expression "an eternal learner", with the aim of highlighting the continuous search for professional development.

Relating to the previous question, the results concerning category 4 , reflective improvement of professional abilities, are found in Table 7, totalizing 76 occurrences.

Table 7. Description of the profile of the reflective teacher.

Category 4 Reflective Improvement of professional abilities

\begin{tabular}{ll}
\hline Subcategories & Oc. \\
\hline Ability to question the practices & 13 \\
\hline Ability to perform critical reflection & 12 \\
\hline Ability to update pedagogical didactics & 10 \\
\hline Ability of the teacher to work collaboratively & 10 \\
\hline Ability to research in action & 8 \\
\hline Ability to improve the quality of teaching & 8 \\
\hline Ability to motivate the students & 7 \\
\hline Ability to improve the quality of the teaching process & 5 \\
\hline Ability to work with the students & 3 \\
\hline
\end{tabular}

In their perceptions, supervisors consider that a reflective teacher improves the ability to question the practices (13) and perform critical reflection (12). Accordingly, they state that reflection improves the ability to update pedagogical didactics (10) and to research in action (8). In general, they point out the ability to improve the quality of teaching (8) and the student's motivation (7). Contrasting with the subcategory teachers' ability to work collaboratively (10), collaborative work with the students (3) registers low values.

Some parts of the interviews made to the supervisors are transcript bellow. These underline the importance of the improvement of professional abilities, aiming a teaching and learning process centered in the student. 
Sup.4: "Undoubtedly, the teacher can, through the means of reflection, improve his professional abilities and, at the same time, go beyond his reflection. The important thing is to never forget that the aim of teaching is to develop the student and his training as a citizen."

Sup.7: "A reflective teacher searches knowledge, and does not wait for training sessions (...) He searches new theories, new authors, therefore the ability to update in pedagogical terms is essential to his professional development. Along with many other abilities (...) such as to know how to work as a team with teachers and students, or to be able to investigate in the classroom. Is does not mean that this is easy, but reflection applied to investigation is a strategy for improvement. “

Sup.8:" Without constant professional reflective improvement there is no evolution in teaching. A teacher who reflects has an active attitude and manages to improve the quality of classroom work and motivate students. But, for that, further investigation and collaborative work are needed, instead of the individual work that is still carried out in so many schools."

The words of the supervisors point to the need of deeper involvement of teachers in their professional improvement. The teacher mustn't be «only waiting», but should work actively contributing to higher quality of the teaching-learning process in classroom. Once again, and for all the mentioned abilities, reflection emerges as more important than action.

\section{CONCLUSION}

The study confirms the central role of reflective practice by teachers, before, during and after action, setting its professional development on a reflective and learning School. Following this new pattern for professional learning, reflection-in-action becomes a strategy and tool for training and teaching improvement. This research demonstrates that both teachers and supervisors perceive and value contextualized reflection, implemented in a systematic and collaborative way, through questioning and investigation-in-action. So, the contribution of reflection to the quality of practice and teaching development, based on the reflective improvement of professional skills in different contexts, is evident.

However, in spite of recognizing the potentials of reflection, teachers are still distant from a reflective teacher profile. As it is recognized by them and confirmed by their supervisors, there is still a long way to go, due to the high complexity of the job itself.

First, reflection continues connected to curricular features of selection and substantiation of contents and activities. Although teachers reveal awareness of the advantages of reflection-in action, the results show that they don't always practice it, once that the reflection processes are not interiorized. As a consequence, instead of becoming a recursive reflection process of reflection, before, during and after action, it is too much centralized on planning and unsystematic interventions. In addition, a certain resistance to reflection after action, related to teachers' evaluation, is confirmed.

Secondly, a shared vision of action is not always perceived in terms of collaborative work among peers, based on reflection and on practice questioning. Moreover, there are still some teachers who understand the teaching practice as the center of teaching knowledge, connected with the construction of the student's learning.

Thirdly, reflective questioning should be anchored on investigation-in-action. Nevertheless, the investigation of practices is unusual among teachers, since it demands investigation skills, a theoretical and practical framework, comprehensive of essential authors and theories for 
Coimbra, M. N., Martins, A. O., Pinto, I. P., \& Duarte, R. S. (2014). Practical reflectivity as a context for teachers' professional development: A mixedmethods study. Advances in Social Sciences Research Journal, 1(8), 176-187

research in the field of Educational Sciences. As this knowledge is only dominated by a few teachers, who usually detain Masters or PHD qualifications, an insignificant value given to investigation and pedagogical update is observed.

In spite of the analyzed constraints, it is important to outstand that, in general, teachers recognize the need of commitment to reflection in community, allowing the development of all the educational actors, teachers and students, in a school perceived as a learning educational community.

Finally, the study enables to conclude that the essence of practical reflectivity is set on the group's interpretation of every day pedagogical experiences and on collaborative work, as paths of creation of the learning community. Thus, the role of reflective teacher, who is able to evaluate and undertake in a sustained and organized way a quality teaching-learning in classroom, is essential.

In a future perspective, the role of the supervisor is also emphasized, for the influence he has and will continue to have in the construction of the reflective teacher. So, the praxis will be able to conceive an interrelation development between those who are implied, and interactive with the context where they move, in order to obtain practice improvement in school community.

\section{References}

Alarcão, I. (2009). Formação e supervisão de professores: Uma nova abrangência. Sísifo, Revista de Ciências da Educação(8), 119-128.

Argyris, C., \& Schön, D. (1978). Organizational learning: A theory of action perspective. Reading, Massachusetts: Addison-Wesley Publishing Company.

Argyris, C., \& Schön, D. (1996). Organizational learning II: Theory, method and practice. Reading, Massachusetts: Addison-Wesley Publishing Company.

Bronfenbrenner, U. (1979). The ecology of human development: Experiments by nature and design. Cambridge, MA: Harvard University Press.

Bronfenbrenner, U. (1994). Ecological models of human development International Encyclopedia of Education (2.nd ed., Vol. 3). Oxford: Elsevier.

Bronfenbrenner, U. (2005). Making human beings human: Bio-ecological perspectives on human development. London: Sage Publications.

Coimbra, M. d. N. C. T., \& Martins, A. M. d. O. (2013). Case Studying Educational Research: A Way of Looking at Reality. American Journal of Educational Research, 1(9), 391-395.

Collier, S. T., Cristol, D., Dean, S., Dana, N. F., Foss, D. H., Fox, R. K., . . Hoffman, J. (2010). The Purposes, Practices, and Professionalism of Teacher Reflectivity: Insights for twenty-first-century teachers and students. Lanham: Rowman \& Littlefield Education.

Dewey, J. (1933). How we think: A restatement of the relation of reflective thinking to the educational process. Boston: D. C. Heath.

Dewey, J. (1938). Experience and Education. New York: Macmillan.

Ercikan, K., \& Roth, W.-M. (2006). What good is polarizing research into qualitative and quantitative? Educational Researcher Journal, 35(5), 14-23.

Glickman, C. D., Gordon, S. P., \& Ross-Gordon, J. M. (2001). Supervision and instructional leadership: A developmental approach (6.th ed.). Boston: Pearson, Allyn and Bacon. 
Hargreaves, A., \& Shirley, D. (2009). The fourth way: The inspiring future for educational change. California: Corwin Press.

Harris, L. R., \& Brown, G. T. L. (2010). Mixing interview and questionnaire methods: Practical problems in aligning data. Practical Assessment, Research \& Evaluation, 15(1), 1-19.

Moon, J. (2004). Reflection in learning and professional development: Theory and practice. Oxon: Routledge.

Nolan, J. F., \& Hoover, L. A. (2004). Teacher supervision and evaluation: Theory into practice. Hoboken: Wiley Jossey-Bass Education.

Pawlas, G. E., \& Oliva, P. F. (2007). Supervision for today's schools (8.th ed.). Indianopolis: Wiley \& Jossey-Bass Education.

Peel, D. (2005). Dual professionalism: facing the challenges of continuing professional development in the workplace? Reflective Practice, 6(1), 123-140.

Perrenoud, P. (1998). Savoir réfléchir sur sa pratique, objectif central de la formation des enseignants? Université de Genève: Faculté de psychologie et des sciences de l'éducation.

Perrenoud, P. (1999). Dix nouvelles compétences pour enseigner: invitation au voyage. Paris: ESF.

Punch, K. (2011). Research Methods in Education (reprinted). London: Sage.

Reams, P., \& Twale, D. (2008). The promise of mixed methods: Discovering conflicting realities in the data. International Journal of Research \& Method in Education, 31(2), 133-142.

Robson, J. (2006). Teacher professionalism in further and higher education: Challenges to culture and practice. London: Routledge.

Rodgers, C. (2002). Defining reflection: Another look at John Dewey and reflective thinking. The Teachers College Record, 104(4), 842-866.

Schön, D. (1983). The reflective practitioner. New York: Basic Books.

Schön, D. (1987). Educating the reflective practitioner: Toward a new design for teaching and learning in the professions. San Francisco: Jossey-Bass.

Schön, D. (1991). The reflective turn: Case studies in and on educational practice. New York: Teachers College Press, Columbia University.

Senge, P. M., Cambron-McCabe, N., Lucas, T., Smith, B., \& Dutton, J. (2000). Schools that learn: A fifth discipline fieldbook for educators, parents, and everyone who cares about education. New York: Doubleday.

Stake, R. E. (1995). The art of case study research. London: Sage.

Yin, R. K. (2011). Qualitative research from start to finish. New York: Guilford Press.

York-Barr, J., Sommers, W. A., Ghere, G. S., \& Montie, J. (2006). Reflective practice to improve schools: An action guide for educators (2.nd ed.). Thousand Oaks: Corwin Press.

Zeichner, K. M. (1993). Action Research: Personal renewal and social reconstruction. Educational action research, 1(2), 199-220.

Zeichner, K. M., \& Liston, D. (1986). Teaching student teachers to reflect. Harvard educational review, 57(1), 1-22. 